\title{
El rojas en tiempos de pandemia, virtualidad y resiliencia.
}

\section{Azucena Ester Joffe}

El 2020 causó estragos en nuestra sociedad global y, por supuesto, también en el plano de lo personal. El comienzo de la pandemia y la "infodemia" fueron como un tsunami que atravesó el espacio público y privado sumergiéndonos en una fragilidad desconcertante. La sobreexposición mediática de los primeros meses nos hizo más permeables a esa amenaza constante, más allá de la medida necesaria y excepcional del "aislamiento social, preventivo y obligatorio". Nuestra cotidianidad quedó como un espectro, entre la vida y la muerte, en tanto las redes sociales se apoderaron de nuestra rutina y "el miedo", con mayor o menor intensidad, fue nuestro enemigo interno ante la situación epidemiológica a nivel mundial.

Desde 1984, el Centro Cultural Rector Ricardo Rojas, en consonancia con el regreso de la democracia, ha desarrollado una variada propuesta, tanto en la programación como en los cursos, a partir del compromiso, de la reflexión y de la experimentación desde un enfoque multidisciplinario. La institución, constantemente visitada, presenta una sólida trayectoria y un indiscutible reconocimiento a lo largo de sus treinta y seis años. Un vital "caos cultural” como lo definió Cecilia Vázquez, actual Coordinadora General de Cultura de la UBA y Directora del Rojas, hace algunos años. Esta multiplicidad de voces se reorganizó durante el 2020 para la inevitable virtualidad, ampliando su comunidad y, obviamente, eliminando las distancias geográficas.

\section{Inicios de la pandemia}

El COVID-19 claramente ha dejado al descubierto la precariedad y la vulnerabilidad en las cuales se desarrollan las expresiones artísticas, en general, y las artes escénicas, en particular. En esta nota intentaremos ver de qué modo el Centro Cultural Rojas modificó su grilla anual en tiempos de "resiliencia" interna, social y cultural. En esta oportunidad realizaremos un recorte desde marzo hasta diciembre del 2020, antes del habitual receso estival.

Durante la primera etapa de la cuarentena se trabajó acondicionando la variedad de propuestas a la nueva realidad. Se decidió concentrar las actividades en las diversas plataformas de la institución: redes sociales, página web y Comunidad Rojas. Así lxs usuarixs pudieron acceder a los contenidos de la programación artística y de los

1. Agradecemos al Centro Cultural Ricardo Rojas por su colaboración para poder realizar esta nota. 
cursos a distancia; si bien esta posibilidad se venía trabajando como una alternativa, con el nuevo escenario se aceleraron los procesos.

En el marco de las actividades del mes de la Mujer y con cuatro obras en cartel -Cosas pesadas caen, de Patricio Ruiz, La Facunda, de Alejandro Santucci, Pampa escarlata, de Julián Cnochaert y No es país para Negras II, de Alejandra Egido-, ante los primeros casos positivos en el país, se comenzaron a tomar medidas preventivas; pero luego, el 19 de marzo, como ya sabemos, la emergencia sanitaria obligó a suspender todas las actividades. Al principio, esta medida se pensó que duraría treinta días pero se terminó necesariamente extendiendo. Al momento de esta escritura, algunas salas teatrales han podido retomar sus actividades presenciales con el correspondiente protocolo.

\section{Artes escénicas}

En relación a las artes escénicas, el Centro Cultural Rojas se focalizó en primer lugar en su canal de YouTube, sumando nuevos contenidos que se fueron replicando o direccionando a las redes sociales. Los distintos posteos con los hashtags \#yomequedoencasa \#somosresponsables, \#noscuidamosentretodos, comenzaron a mostrar su creciente comunidad online.

Especialmente al inicio, se compartieron en su sitio web los registros audiovisuales de distintas obras de teatro y de danza estrenadas en esa normalidad que hoy todxs extrañamos: El fin, de Giuliana Kiersz; Dóberman, de Azul Lombardía; Cyan, de Pilar Fridman; Marisa Wayner Vende, de Consuelo Iturraspe; La mareaúltimo corte, de Josefina Recio; Serétu madre tranquila, de Ariel Gurevich; Mientras muero imagino huevosque se pudren, de Leandro Orellano; Amar, amar, amar, de Manuela Méndez; El estadonatural, de Paula Salomon; La vida feliz, de Pablo Rojas; Polite, de Pablo Sigal; Soñardespierto es la realidad, de Mariana de la Mata; Rastros, de Ana Armas; Furtivo, de David Señoran; Cosas pesadas caen, de Patricio Ruiz; Extraña vecindad, de Virginia Ravenna y Sandro Nunziata; Stabat Mater, de Damián Malvaci; Ensayo $N^{\circ} 2$ - Bandoneón, de Ollantay Rojas; Despojos, de Maximiliano Navarro; La última fábula, de Federico Lehmann; Deisy, de Felipe Villanueva; y El ardor de nuestrxs cuerpxsincendiadxs, resultado de la búsqueda y experimentación del grupo con la dirección de Lucas Nicolás Cardozo y Matias Rebossio.

Posteriormente, a fines de octubre, comenzaron las primeras producciones en una plataforma propia con entradas online a precio accesible e, incluso, en algunos casos, con entrada gratuita a través de la web:

- Desde 4 de noviembre al 20 de diciembre, estuvo disponible nuevamente Cosas pesadas caen, de Patricio Ruiz, $11^{\mathrm{a}}$ edición del Premio Germán Rozenmacher. El registro audiovisual corresponde a las funciones realizadas en el marco del FIBA 2020 (prepandemia). Sin embargo, en esta oportunidad, también se agregó material adicional, testimonios de su director, del elenco y de lxs técnicxs que, en cierto modo, resignificaron la obra en el nuevo contexto. ${ }^{2}$

2. Ficha técnico-artística: Cosas pesadas caen. Dramaturgia y dirección: Patricio Ruiz. Intérpretes: Martin Bontempo, Camila Miranda, Federica Presa y Pablo Seijo. Actuación en video: Miguel Rios, Maria Del Carmen Ruiz y Patricio Ruiz. Vestuario: Javier Mayer. Escenografía: Florencia Miranda. Objetos y máscaras: Sigue Al Conejo Negro. Diseño de luces: Lía Bianchi. Diseño de sonido: Camilo Ortiz. Audiovisuales: Henri Hournau. Fotografía: Julián Larroza. Asistencia de dirección: Sofía De Brea. Producción: Manuela Roca. Co-producción: FIBA, CCRRR (UBA). 

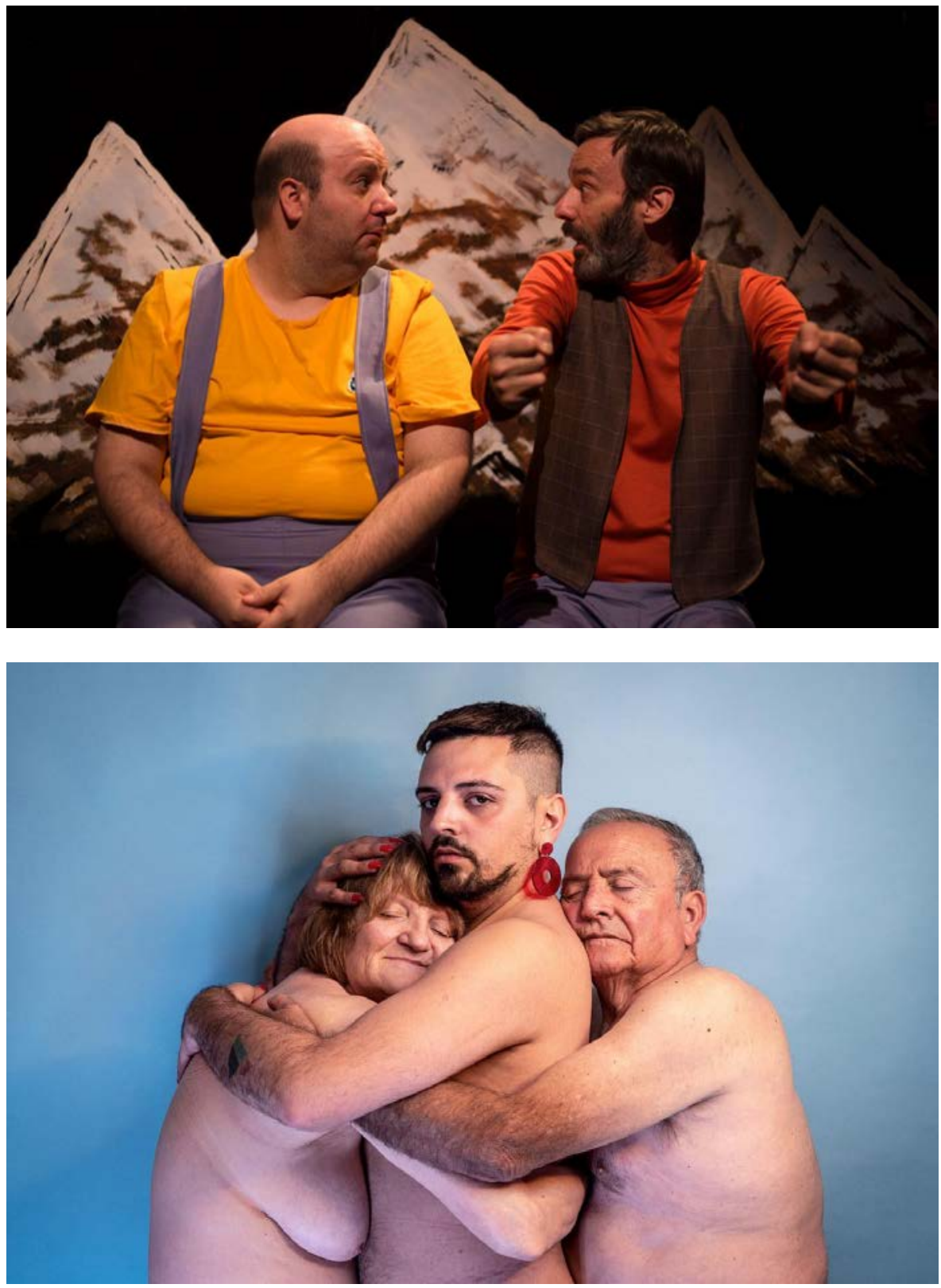

- Desde el 6 al 20 de diciembre, estuvo disponible el cortometraje El fracaso de la bullinera, con guión y dirección de Clara Hails y Sabrina Macchi. Aunque el proyecto, inicialmente, comenzó a gestarse en versión teatral, con fecha de estreno para junio 2020, la irrupción del Covid-19 modificó esa intención creando un "metabiodrama" atravesado por la actual coyuntura pandémica. Las historias particulares de Clara y Male -compañeras de escuela en Chascomús, donde Male sufría bullying- se entrecruzaron con los ensayos en el Rojas, con el registro de entrevistas a transeúntes ocasionales y con el volver a esos sitios que compartieron años atrás. ${ }^{3}$

3. Ficha técnico-artística: El fracaso de la bullinera. Guión y dirección: Clara Hails \& Sabrina Macchi. Género: Docu Ficción. Intérpretes: Clara Hails, Male Ehul y Sol Ajuria. Producción ejecutiva y diseño gráfico: Mar Matilla. Postproducción de sonido: Estudio Móvil. Música original: Javier Guerra \& Lucrecia Massei. Montaje: Tomas Pernich. Cámara: Mar Matilla, Sabrina Macchi, Damian Picardi y Dal Provenzano. 

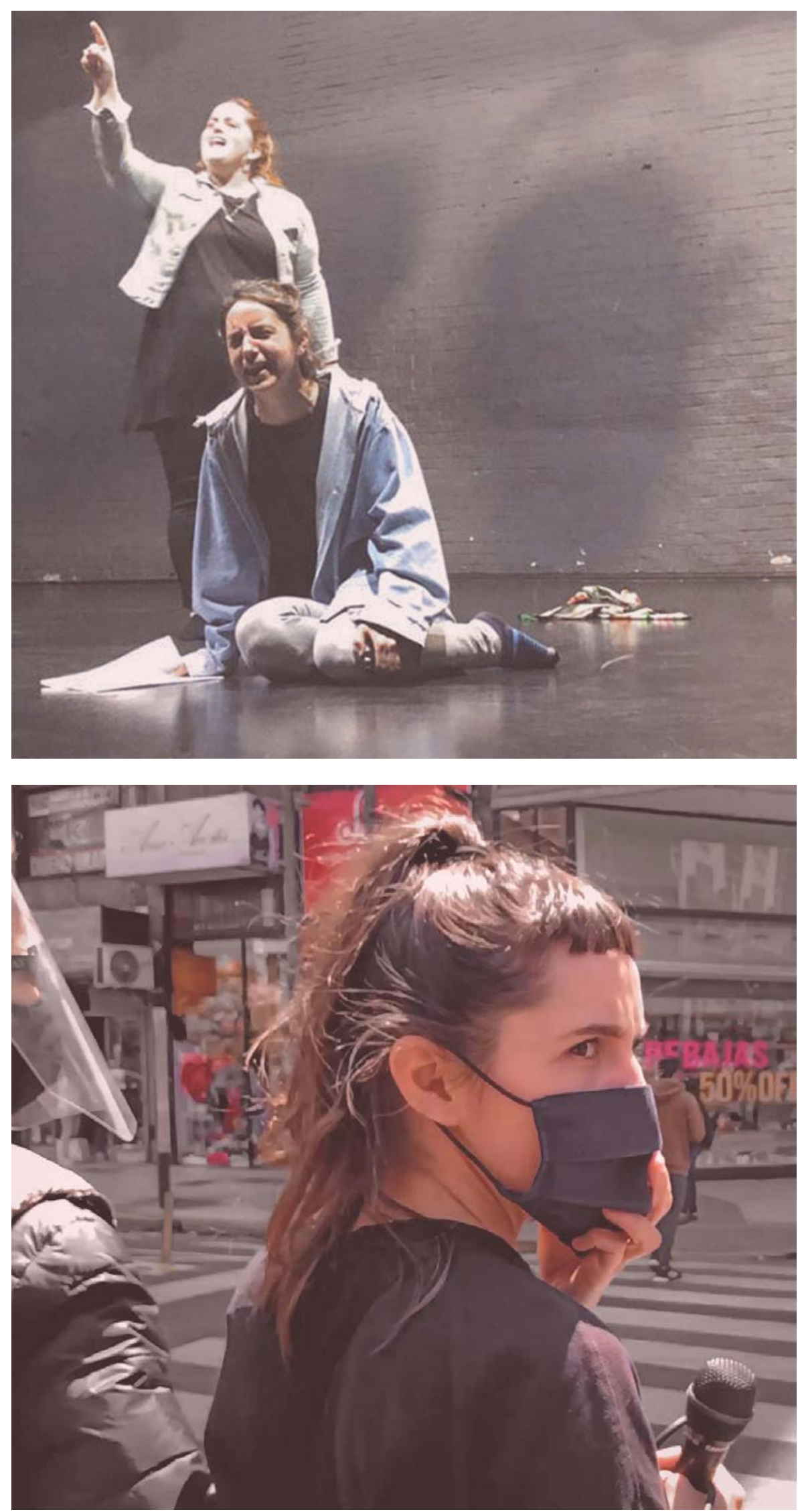
- Desde 6 de noviembre al 20 de diciembre, se presentó con acceso gratuito la inmersión audiovisual Pausa, una realización de EscenaLab-Rojas, encargada especialmente por la dirección del Centro. Posteriormente, también se compartió en su canal de YouTube. La propuesta artística se fue construyendo desde cada hogar pero de forma conjunta y con las herramientas que tenían disponibles en ese momento. Ya desde su título nos convoca, porque sorpresivamente nuestra cotidianidad quedó en "pausa" sin aviso previo. Los instrumentos acústicos y electrónicos, los sonidos de la naturaleza y las imágenes intervienen en un universo envolvente y onírico. ${ }^{4}$

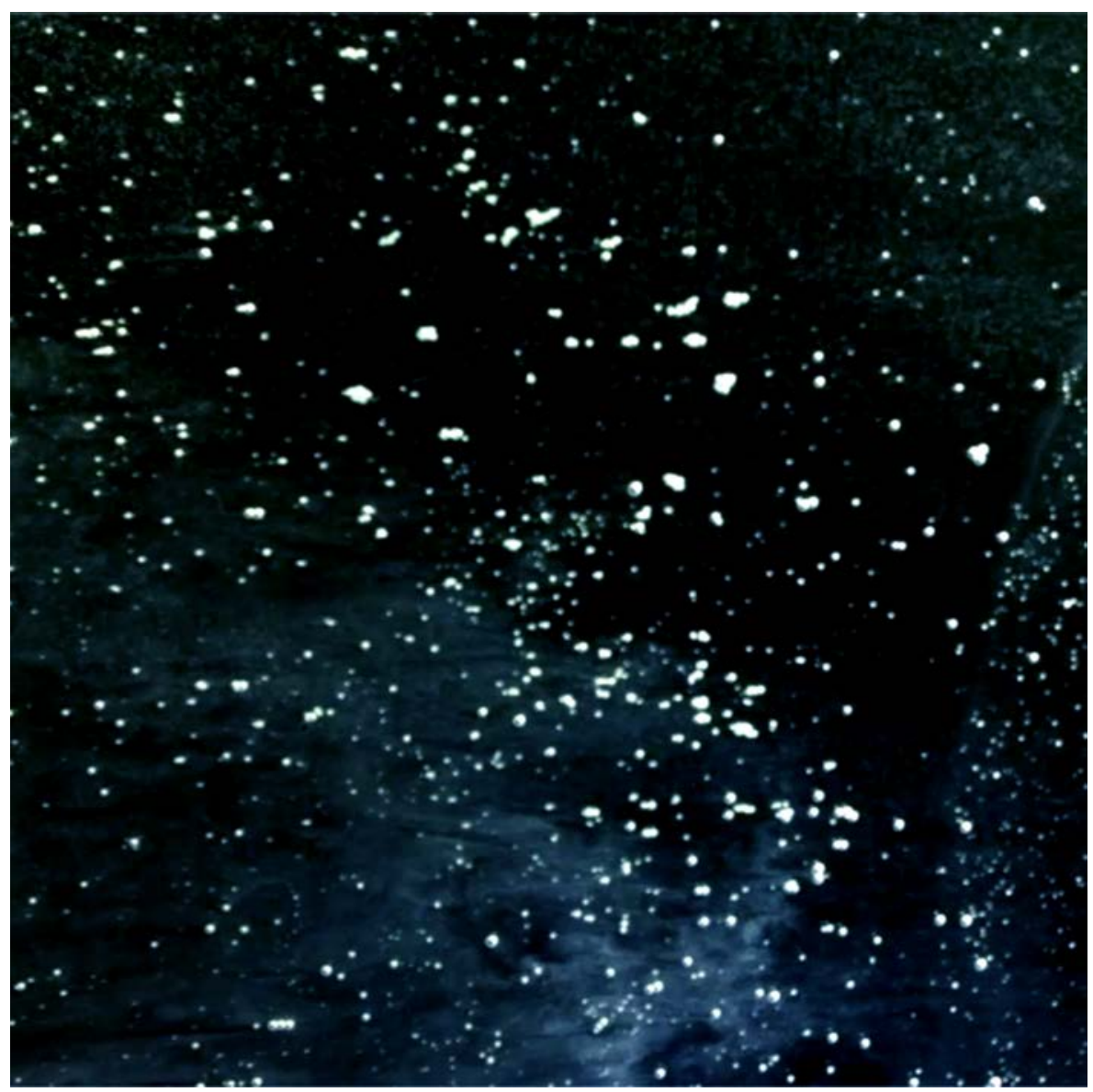

4. Ficha técnico-artística: Pausa. Creación original: Ciro Cavalotti, Guillermo Cardozo Ocampo, GuiIlermo Peloche y Quique Condomí. 


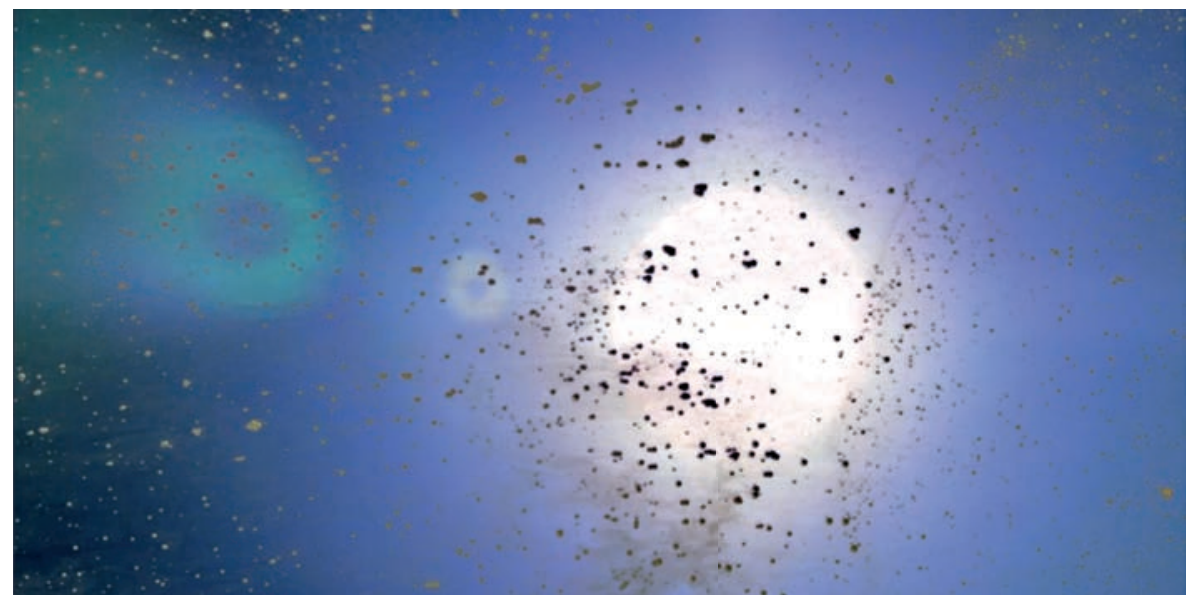

- Desde el 25 de octubre al 29 de noviembre, se desarrolló el ciclo Experiencia Aventura, coordinado por Maruja Bustamante a modo de recorrido performático virtual y vivencial, compuesto por tres obras, disponibles en tres días diferentes:

1) Los sábados se iniciaba la saga con Perritos de porcelana, escrita por Federico Leherman. Cada sábado se presentaba un episodio vía streamingy, durante la semana, el espectador podía continuarlo dirigiéndose a determinados sitios de la ciudad y escaneando el código QR que direccionaba al correspondiente podcast del capítulo. Esteban Lamothe era el guía, mediante mensajes de texto y audios, entre un episodio y otro como también durante el recorrido de un sitio a otro. ${ }^{5}$

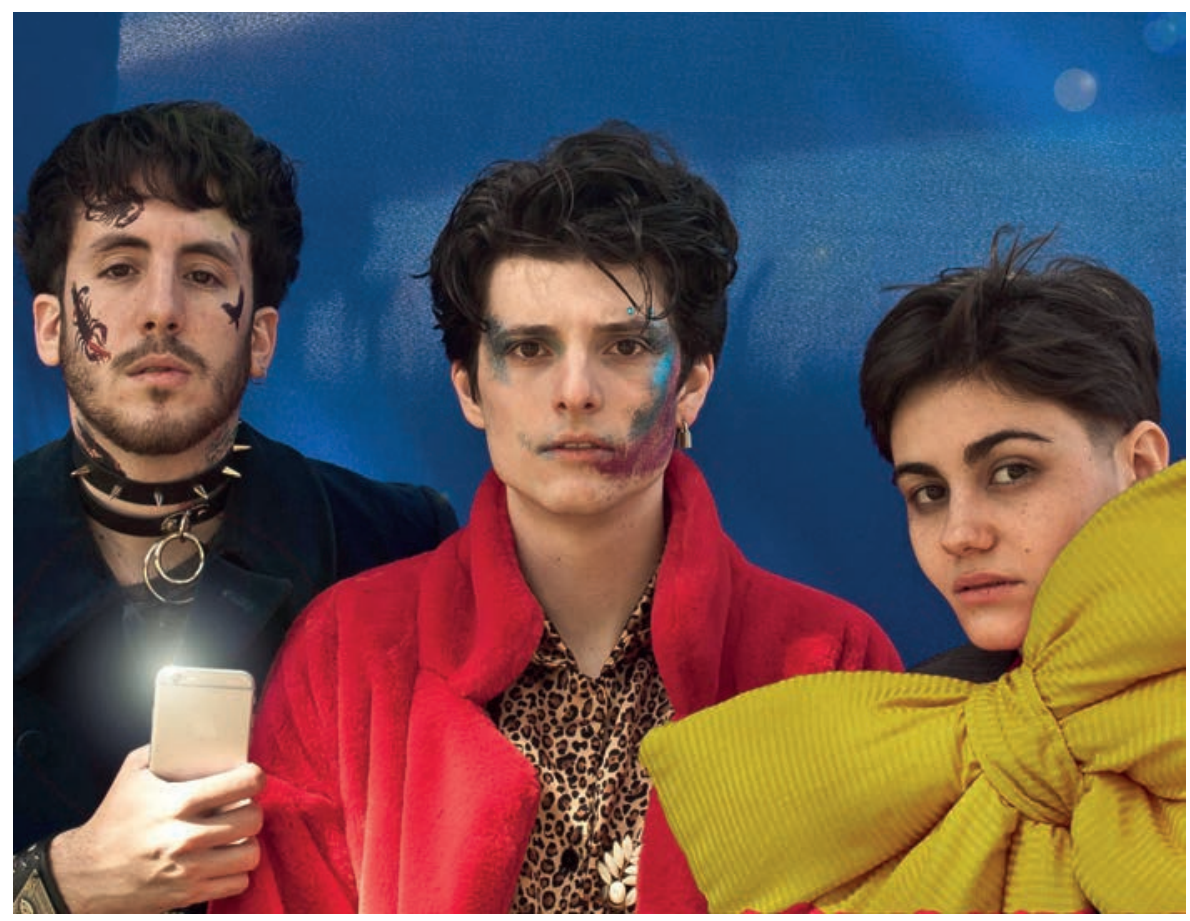

5. Ficha técnico-artística: Perritos de porcelana. Autoría: Federico Lehmann. Intérpretes: Camila Marino Alfonsín, Matias Milanese y Federico Pezet. Vestuario: Denise Gomez. Asistencia de producción y dirección: Francisca Levin. Producción general: Experiencia Aventura, CCRRR (UBA), LosPipis Teatro. Dirección: LosPipis Teatro. 
2) Los domingos continuaba Sentime, de Romina Almiron, una "obra performática y multisensorial". Al ingresar a la plataforma se encontraba una presentación que, en vivo, daba una especie de bienvenida a lxs espectadorxs e invitaba a transitar por esa "isla imaginaria"; a continuación la voz de Juan Minujín lxs introducía en la experiencia "subacuática". 6

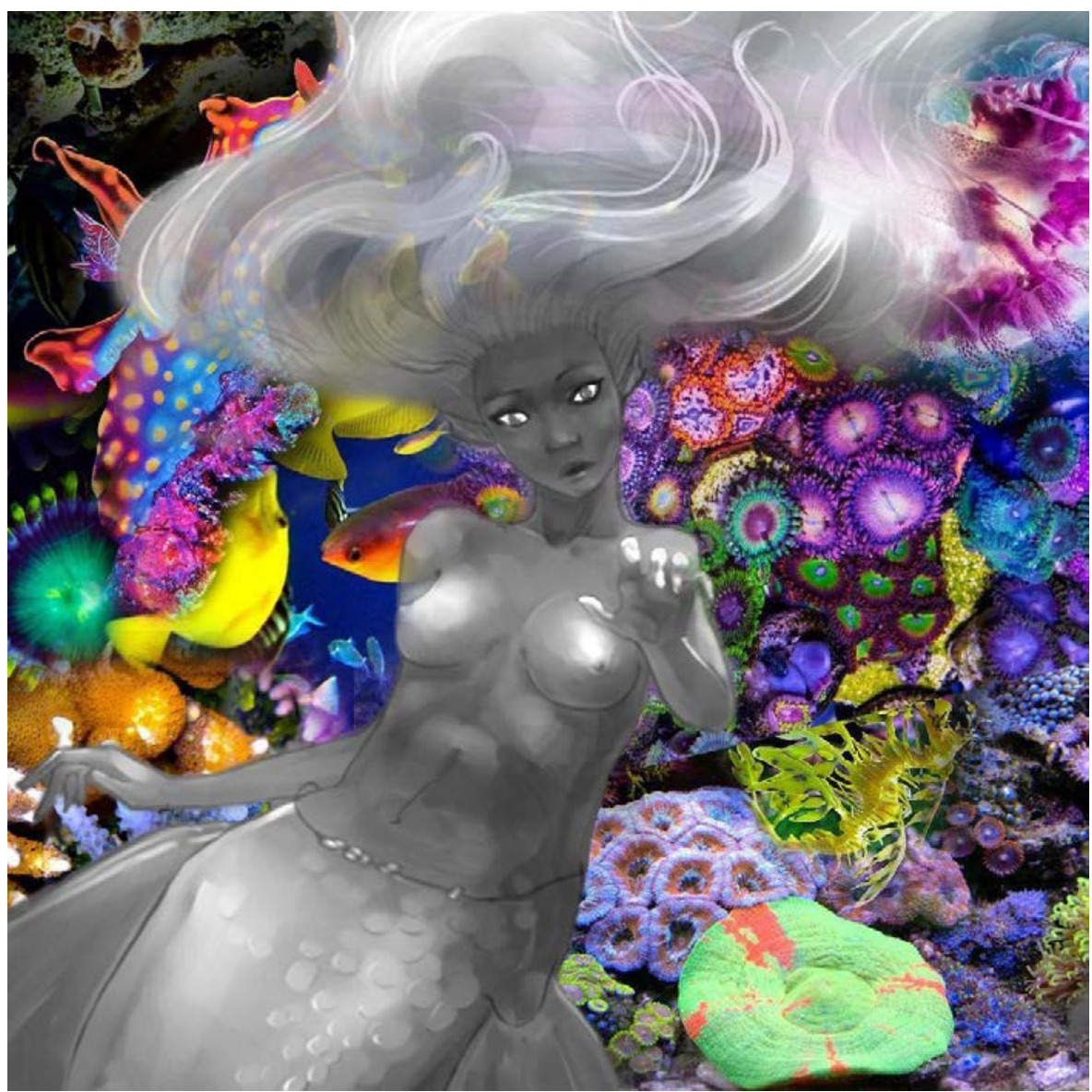

3) Los jueves era el turno de La Verbena: una "fiesta ideal" por streaming, con la participación especial de Sofía Gala, que se iniciaba con una breve presentación. Luego, el grupo de WhatsApp permitía la continuidad durante toda la semana: lxs espectadorxs proponían cosas y las intérpretes enviaban videos o fotos en relación con la temática tratada. Para finalizar esta "performance interactiva", existía la opción con modalidad presencial, y la necesaria distancia, en la esquina de Thames y Loyola. ${ }^{7}$

6. Ficha técnico-artística: Sentime. Autoría: Romina Almiron. Intérpretes: Romina Almiron, Francisco Cruzans, Juan Minujín. Ilustraciones y diseño sonoro: Fabricio Gambatese. Caracterización: Paula Besostri y Florencia Saraceni. Producción: Romina Almiron. Dirección: Romina Almiron y Fabricio Gambatese.

7. Ficha técnico-artística: La Verbena. Intérpretes: Sofía Gala, Virginia Garófalo y Maruja Bustamante. 


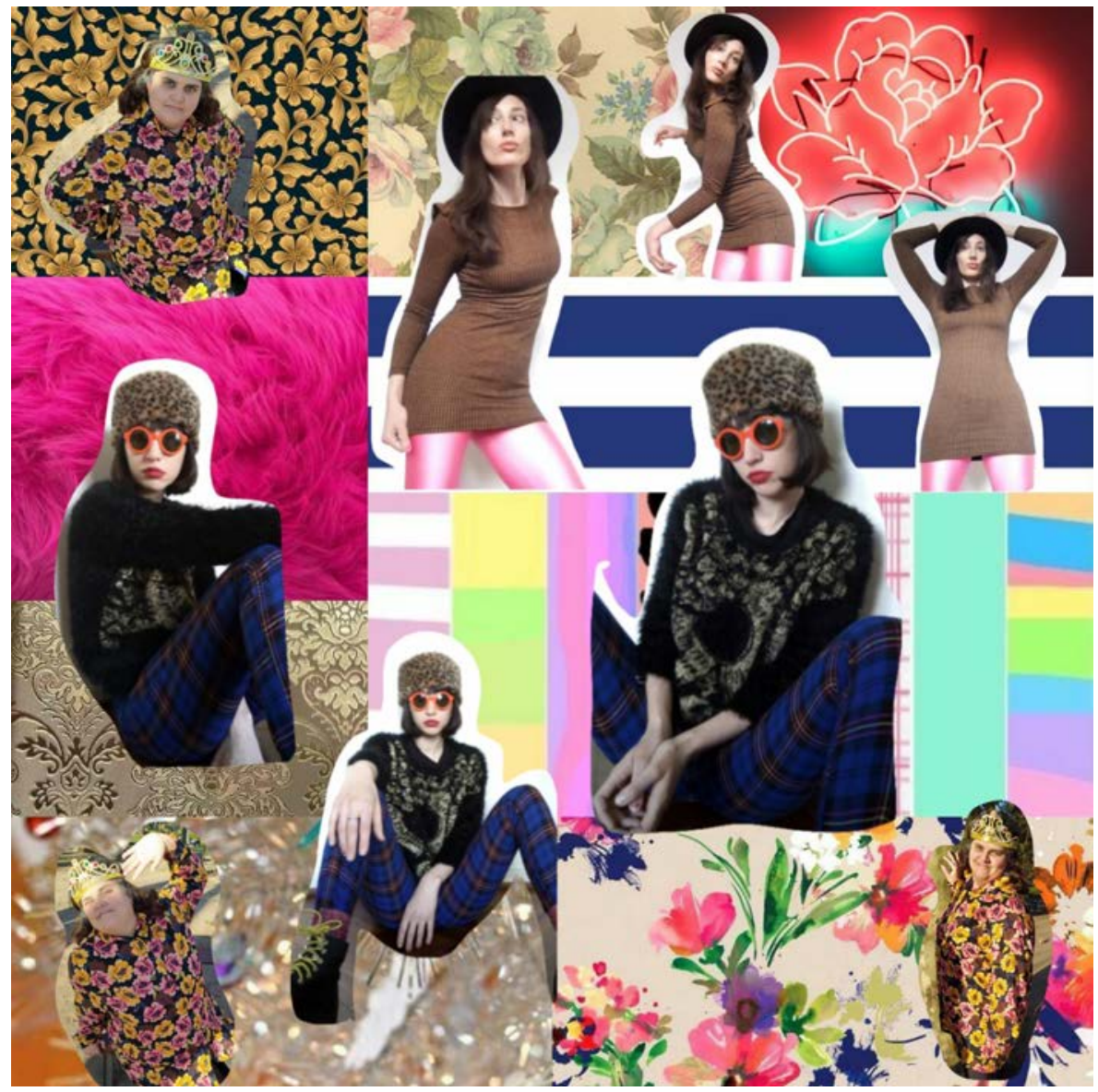

En particular, sobre las propuestas artísticas El fracaso de la bullinera, Pausa y Experiencia Aventura, podríamos decir que su principio constructivo es la situación sanitaria y social, sin precedente, atravesada por la "resiliencia" de lxs artistas y de lxs profesionales y por la "resiliencia" institucional intrínseca del Centro Cultural Rojas. Cabe resaltar, también, que Cosas pesadas caen y El fracaso de bullinera participarán del FIBA 2021 por medio de la plataforma Vivimos Cultura.

Ya finalizando el año, como adelanto del ciclo Proyecto Familia, se subieron al canal de YouTube algunos work in progress de las próximas piezas, que si las condiciones lo permiten, se estrenarán en sala en algún momento de 2021: Espíritu de una obra que todavía no existe, de Maxi Muti; Cohete California, de Agustín Rittano; Doméstica, de María Canale y Sebastián Francia; Las fuerzas, de Damiana Poggi y Nora Lezano; y El otro Onassis, de Beatriz Rippel, de la cual, por el momento, aún no hay registro online.

\section{Otras áreas artísticas}

En relación con las otras actividades que propuso el Centro Cultural Rojas, podemos comentar que en los tiempos del Covid-19 se permitió el acceso a diferentes contenidos con descarga gratuita: El Teje. Primer periódico travesti latinoamericano; Nautilus, revista de divulgación científica; los libros Te lo juro por Batato y Alfonsina periodista, entre otros títulos. Además, se compartió la edición digital de 25 años del Rojas (2009), con testimonios en primera persona, notas periodísticas, entrevistas y material fotográfico. 
En el mes de septiembre, el Centro celebró, por un lado, su aniversario número 36 y, por el otro, los 25 años de su Fotogalería, espacio curado por Alberto Goldenstein desde su inauguración que, en pandemia, se transformó en un recorrido virtual a través del registro de exposiciones pasadas, entrevistas a diferentes artistas y la invitación a lxs asistentes en época de pre-pandemia a que compartieran fotografías tomadas durante aquella visita. Asimismo en el canal de YouTube, se pudo ver la entrevista realizada en el ciclo Rojas Vivo a Goldenstein y, además, el documental Londaibere (2019) realizado conjuntamente por el Rojas y UBA-TV sobre Alfredo Londaibere, importante artista plástico vinculado con el Centro Cultural.

También se pudieron continuar los diferentes ciclos que se transmiten por Radio UBA, con los cambios necesarios para que esos contenidos circulen por las redes: Rojos de Vergüenza, conducido por Gabriel Wolf y Pablo Palavino; Futuro, por Sergio Marchi; Rojas Intenso, con Sebastián Santamaría; Confesionario en tiempos de cuarentena, con Cecilia Szperling; Tren de Noche, con Diego Fischerman; y Truco Gallo, con Alfredo Rosso y Claudio Kleiman.

Asimismo, otras actividades pudieron sostener su continuidad: la convocatoria para "Operas Primas 2020" y la tercera edición de "Maestras"; e incluso surgieron otras nuevas: "Rojas Vivo", con diferentes entrevistadxs vinculadxs al sentir del Rojas; "Aventura", charlas en vivo en un recorrido poco habitual con Maruja Bustamante; "Pálpito", con herramientas y/o sugerencias de distintxs dramaturgxs; y el Área técnica compartió videos sobre la trastienda de la puesta en escena -Iluminación, Sonido, Vestuario, Producción-.

Igualmente, al inicio de la pandemia, lxs diferentes capacitadorxs sumaron a diario diversos tips para que la comunidad online pudiera ocupar ese inevitable "tiempo muerto"; y finalizando el año se compartieron varios podcasts y se realizó la convocatoria al $13^{\circ}$ Premio Germán Rozenmacher de Nueva Dramaturgia, organizado dentro del marco del FIBA 2021. Particularmente, la artista visual Fabiana Barreda mantuvo de forma virtual su ciclo de conferencias de libre acceso e inscripción previa: la primera conferencia se realizó en agosto, "El cuerpo hoy: Deconstrucción y feminismos. Debate postpandemia", y la segunda, "Cuerpo y Neo-feminismo. Arte contemporáneo y cuerpo social", se dividió en dos partes: en octubre, "Cuerpo y Tecnología. Neo-feminismo" y, en noviembre, "Cuerpo y Escultura Social. Neo-feminismo". Igualmente, bajo la misma modalidad, el músico e investigador Coco Romero, claro referente del Centro, con más de treinta años desarrollando distintas actividades relacionadas con el carnaval, en general, y a la murga, en particular, continuó con talleres, consultorías y publicaciones.

Sin excepción, el Centro estuvo presente en distintas fechas importantes compartiendo posteos para mantener viva nuestra memoria colectiva, como el Día de la Memoria por la Verdad y la Justicia; el Día del veterano y los caídos en la Guerra de Malvinas; el día de La Reforma Universitaria; el Día Internacional del Orgullo LGBTIQ; el Día Internacional de la Eliminación de la Violencia contra la Mujer; y, por supuesto, se sumó a la despedida del gran creador Quino. La actividad conmemorativa se desarrolló sin olvidar las importantes recomendaciones para evitar el contagio del Covid-19 y el agradecimiento a todxs aquellxs que estuvieron presentes desde el primer momento mientras nos recordaban \#quedateencasa.

\section{Último comentario}

En medio de un panorama tan incierto y tan duro como lo fue el año pasado, podemos inferir que el balance parece ser positivo. Durante el 2020, se multiplicaron los 
cursos, seminarios y talleres -algunos con bajo arancel y otros gratuitos- para todas las edades, desde lxs más pequeñxs hasta lxs adultos mayores. En particular, en abril el Centro Cultural Rojas ofreció una interesante capacitación online, con inscripción previa, para docentes de todo país de nivel inicial y de primaria: "Música con tablet y dispositivos móviles".

Actualmente se están ofreciendo más de 200 cursos a distancia por cuatrimestre que se pueden realizar de manera sincrónica y asincrónica, casi acercándose a la oferta que había antes del actual contexto. La respuesta de lxs alumnxs ha sido muy entusiasta, superando en algunos cursos las cantidades usuales de inscripciones, con estudiantes de todo el territorio nacional e incluso del extranjero. Efectivamente, la opción de la virtualidad permitió acercarse a nuevos y variados públicos. Arte y tecnología, música, humanidades, idiomas, informática, oficios, letras y literatura y actividades para lxs niñxs estuvieron y seguirán estando entre las propuestas, siempre a cargo de expertxs capacitadxs.

Respecto a la cartelera de espectáculos, las audiencias por streaming cumplieron un importante rol, alentando a seguir generando más producciones. Todo pareciera indicar que el futuro de las artes seguirá un camino híbrido entre lo presencial y lo virtual, y el Centro tendrá la impronta de reflexión y de experimentación que caracteriza su historia. Es por eso que en marzo de 2021 estará en funcionamiento la nueva web del Rojas (https://www.rojas.uba.ar/), presentando un diseño que agilizará el contacto con los diferentes sectores de la comunidad.

Desde la institución se irán viendo, paso a paso, las posibilidades en este nuevo escenario. Por lo pronto están preparando un mix de actividades virtuales y presenciales -que exceden a las artes escénicas- para realizar al aire libre, en el marco de los festejos de los 200 años de la Universidad de Buenos Aires. En función de lo que la "nueva realidad" permita, se enfatizará una modalidad u otra o se harán convivir ambas. La idea es posibilitar en el futuro un sistema mixto, en el cual lo virtual y lo presencial coexistan.

Al inicio de la pandemia, cuando la incertidumbre, los momentos de vacío y la indispensable conectividad modificó nuestro lugar de confort, el Centro Cultural Rojas visibilizó las diferentes realidades con el mismo compromiso y con la misma pasión artística que indudablemente lo establece como vital "caos cultural". 


\section{Dibliografía}

»Vázquez, C. (2009). “Referente para la innovación” en 25 años del Rojas. Recopilado por Natalia Calzon Flores. Buenos Aires: Libros del Rojas. https://www. rojas.uba.ar/storage/books/JKpVZ43Rg2jncYGQwf435LDw4b6Q4tS2Q gxuEkEr. pdf 